A double-blind placebo controlled cross-over trial was carried out to assess the efficacy of ketotifen in pre-school asthmatics. The trial. period consisted of a 1 month run-in and two 6 month treatment periods, with ketotifen $1 \mathrm{mg} \mathrm{b.d}$. or placebo, separated by a 1 month wash-out. 47 children with moderate to severe asthma completed the study. There were 29 boys and 18 girls age ranged from 1 yr 10 months to 5 yrs 11 months (mean 4 yr +1 yr 3 months). In addition to the study treatment, patients were managed conventionally with beta agonists, theophylline, cromoglycate, inhaled oral steroids. Throughout the study attempts were made to reduce medications to the minimum level compatible with good symptom control. Patients were seen monthly (by BCr) and parents completed a diary card between visits. Benefit was assessed by comparing synptoms of asthma and rhinitis, concomitant medication, and parental and physician preference for the two treatment phases. A preliminary analysis of the data suggests that there was an order effect with symptom control improving and concomitant medication increasing throughout the study period. When active and placebo treatments were compared there was little difference with respect to symptom control, or level of concomitant medication. There was no clear preference expressed for active or placebo therapy. Ketotifen was well tolerated and was associated with increased weight gain.

151 EFFDCT OF NIFEDIPINE ON THE HISTAMINE (H) OR ACETYLCHOLINE (A) INDUCED BRONCHOCONSTRICTION CONTROLLED BY PHARMACOCAPNOGRAPHY.

K.Gyurkovits and Z.Toldi. Ped.Dept.Univ. Med.School of Szeged, Hungary

Before and after administration of the $\mathrm{Ca}^{++}$channel blocker nifedipine (Corinfar, GDR), bronchiel provocation tests were performed in asthmatic children displaying an enhanced respiratory sensitivity to $B$ and $A$ aerosols.Continuous challenges with $0.05 \%$ H resp. with $0.1 \%$ A solution were admintstered for max. 15 minutes. Computerised on-line $\mathrm{CO}_{2}$ analysis of exhaled air (Jaeger $\mathrm{CO}_{2}$ Test) was used to detect subclinical bronchoconstriction. The results revealed full protection against the effect of II from a single oral dose of Corinfar in 4 out of 17 cases, and partial protection in 10 out of 17 cases. spondine data fox $A$ were 5 and 7 out of 17 cases, respectively. Thus, Corinfar exerts a sifnificant proteotive effect against both types of provocation. The lower sensitivity of spirometry than that of capnography meant that, although moderate protective effects could be demonstrated, these were not mathematically significant. The $\mathrm{Ca}^{++}$chanmel blockors may be useful anclliary afents in the complex treatment of patients with bronchial hyperreactivity, partly because they decrease the bronchial swooth muscle spasm, partly because they inhibit the release of active mediatoxs.

Ref.: Barmes: Calcium-channol blockers and asthma. Thorax $38,481,1983$.

\section{NEBULISED BECLOMETHASONE DIPROPIONATE SUSPENSION}

MSC Webb, AD Milner, EJ Hiller, RL Henry Dept. of Child Health, Queen's Medical Centre, Nottingham, England.

The role of beclomethasone in childhood asthma is established, but the efficacy of the suspension form in clinical practice is unconfirmed. In a double blind cross-over trial, we compared beclomethasone dipropionate with placebo in 16 children less than 6 years old (mean age 40.9 months). Each child received nebulised solutions containing $150 \mathrm{mcg}$ of beclomethasone or $3 \mathrm{mls}$ of water three times per day, each for two months, as the sole form of prophylaxis. Three children abandoned the trial prematurely due to marked worsening of symptams, one during the first treatment period and two during the second treatment period - each was receiving placebo at the time. Parental preference indicated beclamethasone superior to placebo in 11 children. Of the 13 children who completed the trial, eight were improved on beclomethasone and five on placebo. There were no significant differences in daily symptam scores, bronchodilator and oral corticosteroid use or number of symptom free days. No side effects of active treatment were noted. These results show that beclomethasone dipropionate suspension may be an effective treatment in young children, though the figure of five who were better on placebo is disappointingly high. Further clinical studies are urgently needed.
153 ANTIASTHMATIC EFFECTS OF ONIONS - THIN LAYER CHROMATOGRAPHY FOR IDENTIFICATION OF THE ACTIVE COMPONENTS?

W. Dorsch and P. Rohsum, Kinderpoliklinik, University,

Recently we reported on asthmaprotective effects of onions (Agents \& Actions 14:262,1984, Eur. J. Pharmacol. $107: 17,1985)$. Now we are trying to identify their active component $(s)$.

Groups of 8-10 guinea pigs were sensitized to ovalbu= min (OA) and challenged by OA inhalations as described. Their asthmatic reactions were quantificated as $\mathrm{ml} \mathrm{com}-$ pressed air by whole body plethysmography. / Onion juice was obtained by sqeezing onions and lyophilized. Thin layer chromatography (Silica gel Woelm 63200 , chloroform/methanol 70/30, 65/35, 60/40, 50/50, 100/0 (v/v)) of fresh onion juice gave 6 subfractions. / 30 min.prior to the $O A$ challenges the animals were fed with $1 \mathrm{mi}$ lyophilized onion juice $(1-100 \mathrm{mg} / \mathrm{kg})$, its subfractions or saline (= solvent of both)

The whole extract prevented the astrmatic reactions in a dose dependent fashion: $100 \mathrm{mg} / \mathrm{kg}: 91 \%, 50 \mathrm{mg} / \mathrm{kg}$ : $86 \%(\mathrm{p}<0.005), 20 \mathrm{mg} / \mathrm{kg}: 68 \%(\mathrm{p}<0.05), 1 \mathrm{mg} / \mathrm{kg}: 46 \%$ ( $p>0.05$, t-test for unpaired data)). Most active was subfraction 6 a dosage of $20 \mathrm{mg} / \mathrm{kg}$ being equipotent to $100 \mathrm{mg} / \mathrm{kg}$ of the whole extract. It contains at least 8 different substances. Their biological activity will be tested in future experiments.

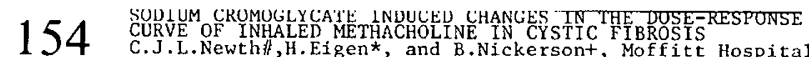

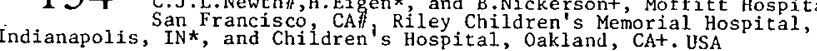
Patients with Cystic Fibrosis (CF) have an increased incidence of also an increased skin reactivity to inhaled allergens anc ail increas ed incidence of allergic rhinitis. Thus, CF shares some clinical features with asthma and drugs used in asthma may be useful in $\mathrm{CF}$. Sodium cromoglycate (SCG) is efficacious in asthma, blocking some
patients against MCh challénge and decreasing bronchial hyper-reactivity. WE studied the potential role of SCG in CF by determining if it could block acute bronchoconstriction induced by MCh, and predict CF patients whose bronchial hyper-reactivity and symptoms would lessen Fifteen CF patients known to respond to an MCh challenge were studied None had clinical asthma, nor had intercurrent infections at the time
of the study. Three standard MCh challenges were performed on consecof the study. Three standard MCh challenges were performed on consecone after $2 \mathrm{ml}$. $1 \%$ scG, which were given in random order in a double-
blind manner. As well as providing a baseline, the two placebo studies provided a measure of the reproducibility of the MCh challenge (variation less than $10 \%$ ). There were only small changes in FEVl after placebo and SCG (1ess than 6\%). The mean FEVl was $65 \%$ (range 32-90) and PD20 was calculated from the dose-response curves of cumulative
MCh inlialed versus drop in FEVI. Four patients (27\%) were completely MCh inlaled versus drop in FEVI. Four patients (27\%) were completely
protected by SCG. We conclude that longterm trials of SCG in CF are

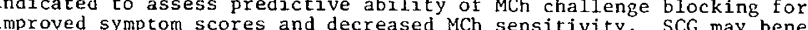
mproved symptom scores and
fit selected CF patients.

(Introduced by Melvin M. Grumbach, M.D.)
155 EFFECT OF INHALED AZLOCILIIN, MISTABRON AND COMBINATTON THERAPY TN CEIIDREN WITH CYSTIC FIBROSIS.
$J$ Stroobant, D P Heaf, S Tyson and D J Matthew Hospital for Sick Children, Great Ormond Street, Iondon, WC1N 3JH, UK Previous clinical trials have shown a beneficial effect of inhaled antibiotics and mucolytics in cystic fibrosis. In vitro studies have suggested significant enhancement of azlocillin inhibition of Pseudomonas aeruginosa by the addition of the mucolytic, mistabron (sodium 2 mercaptoethane sulphonate). We compared the clinical effect of inhaled azlocillin, mistabron and azlocillin combined with mistabron in 21 children with cystic fibrosis aged 6 to 15 years, chronically infected with Ps. aeruginosa, using a double blind cross over design with random order of 4 month treatment periods separated by 2 month treatment-free periods. 18 patients completed the study. The number of respiratory infections during combination therapy was significantly less compared with azlocillin $(p<0.01)$ and mistabron $(p<0.01)$. The number of hospital admissions was also less during combination therapy, compared with mistabron $(p<0.02)$. Percentage weight gain was significantly more durins combination therapy comare with mistabron $(\mathrm{p}<0.05)$. Lung function, chest $X$-ray scores and ventilation/perfusion lung scan scores were not significantly different during any treatment period. No apparent allergic, bronchospastic or other adverse reactions to treatment were noted. Although resistance of $\mathrm{PS}_{\mathrm{S}}$. aeruginosa to azlocillin did develop during all 3 treatment perioda, in no case did it persist. Combination therapy with inhaled azlocillin and mistabron is superior to either treatment used alone. These results support previous in vitro findings that inhibition of Ps. aeruginosa by azlocillin is enhanced by mistabron. 